\title{
Review
}

\section{Cyclophilin A: a key player for human disease}

\author{
P Nigro*,1, G Pompilio ${ }^{1}$ and MC Capogrossi ${ }^{2}$
}

Cyclophilin A (CyPA) is a ubiquitously distributed protein belonging to the immunophilin family. CyPA has peptidyl prolyl cis-trans isomerase (PPlase) activity, which regulates protein folding and trafficking. Although CyPA was initially believed to function primarily as an intracellular protein, recent studies have revealed that it can be secreted by cells in response to inflammatory stimuli. Current research in animal models and humans has provided compelling evidences supporting the critical function of CyPA in several human diseases. This review discusses recently available data about CyPA in cardiovascular diseases, viral infections, neurodegeneration, cancer, rheumatoid arthritis, sepsis, asthma, periodontitis and aging. It is believed that further elucidations of the role of CyPA will provide a better understanding of the molecular mechanisms underlying these diseases and will help develop novel pharmacological therapies.

Cell Death and Disease (2013) 4, e888; doi:10.1038/cddis.2013.410; published online 31 October 2013

Subject Category: Experimental Medicine

\section{Facts}

- CyPA is a critical mediator for cardiovascular diseases.

- High CyPA expression correlates with poor outcome of patients with inflammatory diseases.

- CyPA regulates the infection and replication of several viruses affecting humans.

- CyPA is generally overexpressed in cancer and regulates malignant transformation and metastasis.

- CyPA is a crucial mediator in Alzheimer disease and amyotrophic lateral sclerosis.

- CyPA secretion increases during pro-inflammatory diseases, such as rheumatoid arthritis, sepsis and asthma.

- CyPA expression increases with aging.

\section{Open Questions}

- Deepen the mechanisms by which CyPA contributes to the development of human diseases.

- Identify novel CyPA receptors able to explain all of the cellular events associated with CyPA.

- Design therapeutic agents with the capacity to block specific functions of CyPA while leaving other functions unaffected and without any effect on other CyP isoforms.
Cyclophilins (CyPs) are a family of ubiquitous proteins evolutionarily well conserved and present in all prokaryotes and eukaryotes. ${ }^{1}$ They have peptidyl prolyl isomerase activity, which catalyzes the isomerization of peptide bonds from trans form to cis form at proline residues and facilitates protein folding. ${ }^{2}$ Human CyPs consist of 16 family members that are structurally distinct. Among them, the most abundant member is CyPA, which makes up $\sim 0.1-0.6 \%$ of the total cytosolic proteins. ${ }^{1,3}$ CyPA was initially purified from bovine thymocytes and identified as the primary cytosolic binding protein of the immunosuppressive drug cyclosporin A (CsA). ${ }^{4}$

CyPA is believed to have important roles in many biological conditions including protein folding, trafficking, and T-cell activation (Table 1).

Although CyPA is present intracellularly, it can be secreted from cells in response to inflammatory stimuli such as hypoxia, infection, and oxidative stress. ${ }^{21,24-26}$

The secreted form of CyPA may mediate intercellular communication acting as an autocrine/paracrine factor. In fact, it was shown that extracellular CyPA stimulates proinflammatory signals in endothelial cells (EC) and vascular smooth muscle cells (VSMC), ${ }^{21,26}$ and it is a nonmitogenic survival-enhancing autocrine factor that contributes to mouse embryonic stem cell growth. ${ }^{27}$ Further, extracellular CyPA has a potent chemotactic effect on leukocytes, monocytes, and lymphocytes. ${ }^{25,28}$ The chemotactic activity of CyPA is

\footnotetext{
${ }^{1}$ Centro Cardiologico Monzino-IRCCS, Laboratorio di Biologia Vascolare e Medicina Rigenerativa, Milan, Italy and ${ }^{2}$ Laboratorio di Patologia Vascolare, Istituto Dermopatico dell'Immacolata-IRCCS, Rome, Italy

*Corresponding author: P Nigro, Laboratory of Vascular Biology and Regenerative Medicine, Centro Cardiologico Monzino-IRCCS, Via Parea 4, 20138, Milan, Italy. Tel: +39 02 58002028; Fax: +39 02 58002342; E-mail: patrizia.nigro@ cardiologicomonzino.it

Keywords: CyPA; cardiovascular diseases; viral infections; neurodegeneration; cancer; rheumatoid arthritis

Abbreviations: EC, endothelial cells; VSMC, vascular smooth muscle cells; ROS, Reactive Oxygen Species; ERK1/2, Extracellular signal-regulated kinase 1/2; Ang II, angiotensin II; BM, bone marrow; LDL, low-density lipoprotein; VCAM-1, vascular cell adhesion molecule 1; eNOS, endothelial nitric oxide synthase; KLF2, kruppel-like factor 2; TNF $\alpha$, tumor necrosis factor alpha; Vpr, viral protein R; IFN-I, interferon type I; M1, matrix protein 1; HRE, hypoxia response element; MMP, metalloproteinase; NS5A, non-structural 5A; IL, interleukin; MRP, multidrug resistance-associated protein; MGST1, microsomal glutathione S-transferase 1; GSTZ1, glutathione transferase zeta 1; ABC, ATP-binding cassette; AIF, apoptosis-inducing factor; SOD1, superoxide dismutase-1; NF- $\kappa$ B, nuclear factor kappa B; NF-AT, nuclear factor from activated T cells; pIFN- $\alpha$, pegylated interferon-alpha

Received 16.7.13; revised 10.9.13; accepted 11.9.13; Edited by G Melino
} 
Table 1 Major CyPA functions in protein folding and trafficking, T-cell activation and cell signaling

\begin{tabular}{|c|c|c|c|}
\hline $\begin{array}{l}\text { CyPA } \\
\text { functions }\end{array}$ & CyPA targets & CyPA effects & References \\
\hline \multirow[t]{5}{*}{ Folding } & HIV-1 Gag & Promotion of both the formation and the infectivity of virions of HIV-1 & 5,6 \\
\hline & $\begin{array}{l}\text { Homo-oligomeric a7 neuronal nicotinic } \\
\text { receptor (nAChR) and type } 3 \text { serotonin } \\
\text { receptor }(5 \mathrm{HT} 3 \mathrm{R})\end{array}$ & Maturation of the homo-oligomeric receptor & 7,8 \\
\hline & Collagen & Acceleration of the folding of the procollagen I & 9 \\
\hline & Transferrin & Acceleration of an initial stage in transferrin folding & 10 \\
\hline & Drosophila rhodopsin & $\begin{array}{l}\text { Folding and stability of R1-6 rhodopsin by the NinaA-encoded protein } \\
\text { (an eye-specific CyP) }\end{array}$ & 11,12 \\
\hline \multirow[t]{6}{*}{ Trafficking } & Apoptosis-inducing factor (AIF) & $\begin{array}{l}\text { Co-translocation to the neuronal nuclei to induce cell death after cerebral } \\
\text { hypoxia-ischemia and ALS }\end{array}$ & 13,14 \\
\hline & $\begin{array}{l}\text { Heterogeneous nuclear ribonucleoprotein } \\
\text { A2 (hnRNP A2) }\end{array}$ & $\begin{array}{l}\text { CXCR4-mediated nuclear export of hnRNP A2, nuclear translocation of } \\
\text { ERK1/2, and chemotactic cell migration }\end{array}$ & 15 \\
\hline & CD147 & Transport to the plasma membrane & 16 \\
\hline & Asialoglycoprotein receptor (ASGPR) & $\begin{array}{l}\text { Distribution of ASGPR between the plasma membrane and the endosomal } \\
\text { pool }\end{array}$ & 17 \\
\hline & Fructose-1,6-bisphosphatase (FBPase) & Import of FBPase into intermediate transport vesicles for vacuole delivery & 18 \\
\hline & Zinc-finger protein 1 (Zpr1) & Promotion of nuclear export & 19 \\
\hline \multirow{3}{*}{ Cell Signaling } & Interleukin-2 tyrosine kinase (Itk) & Positive regulation of Th1 profile and inhibition of Th2 differentiation & 20 \\
\hline & $\mathrm{ERK} 1 / 2$ & Stimulation of VSMC growth & 21,22 \\
\hline & $\begin{array}{l}\text { JNK, p38 kinase, and lkB, NF-kB, } \\
\text { E-selectin, and VCAM-1 }\end{array}$ & Stimulation EC apoptosis and inflammation & 23 \\
\hline
\end{tabular}

mediated, in part, through the activation of the ubiquitous Ig like CD147 cell receptor. ${ }^{29}$

A growing body of evidence suggested its involvement in key processes underling human pathologies. The objective of this article is to review the current knowledge of CyPA regarding its potential role in several human diseases in order to offer novel therapeutic strategies.

\section{CyPA and Cardiovascular Disease}

Vascular remodeling. It has become clear that increases in reactive oxygen species (ROS) and inflammation represent key pathogenic mechanisms for vascular disease. For example, ROS have been implicated in the pathogenesis of neointima formation in part by promoting VSMC growth as well as stimulating pro-inflammatory events. ${ }^{30}$ In light of the major importance of CyPA in those aspect closely related to vascular remodeling, we analyzed the response to complete carotid ligation in wild-type (WT) mice, CyPA knockout $\left(\mathrm{CyPA}^{-l^{-}}\right)$mice, and mice overexpressing CyPA specifically in VSMC (termed VSMC-Tg). ${ }^{22}$ Analysis of ligated arteries revealed that the intimal area as well as medial and adventitial thickening were significantly lower in $\mathrm{CyPA}^{-1-}$ mice and significantly enhanced in VSMC-Tg mice versus WT mice. Interestingly, there was a significant decrease in the recruitment of inflammatory cells in ligated arteries of $\mathrm{CyPA}^{-1-}$ mice and a significant increase in VSMC-Tg mice (approximately twofold) compared with WT mice. In addition, extracellular signal-regulated kinase 1/2 (ERK1/2) activation and $\mathrm{Ki}^{+} 7^{+}$cells were consistently decreased in $\mathrm{CyPA}^{-/-}$ mice after carotid ligation. These data strengthen the link between CyPA expression and VSMC proliferation and suggest that VSMC-derived CyPA is important for the recruitment of inflammatory cells.

Abdominal aortic aneurysm (AAA). Inflammation has long been known to contribute to the pathogenesis of AAA. More than a decade ago, it was shown that treatment with CsA attenuated the formation of AAA in the rat model of elastase infusion. ${ }^{31}$ The authors of that study pointed out that the immunosuppressive effects of CsA would probably preclude its use in patients with aneurysms. We have recently demonstrated that deletion of CyPA in mice prevents the formation of AAA in response to infusion of angiotensin II (Ang II). ${ }^{32}$ Importantly, mice lacking CyPA were completely protected against aortic rupture leading to sudden death. Mechanistic studies revealed that deletion of CyPA reduces aortic inflammation, oxidative stress, and matrix degradation (Figure 1). In a series of experiments involving bone marrow (BM) transplantation, as well as experiments in which CyPA was selectively overexpressed in VSMC, we showed that expression of CyPA in VSMC, rather than BM-derived cells, is crucial to the development of AAA. Finally, to demonstrate its relevance to human aneurysmal disease, we showed that Ang II caused the release of CyPA and the activation of metalloproteinase 2 (MMP-2) in VSMC derived from human AAA.

Recently, Prins et al. ${ }^{33}$ found that benzo[a]pyrene potentiates the pathogenesis of AAA by increasing CyPA expression. Furthermore, simvastatin-treated patients with AAA exhibited lower CyPA mRNA, as well as CyPA intracellular protein levels. ${ }^{34}$ Thus, the interference with signaling pathways leading to CyPA may reveal a new strategy in the treatment of $A A A$.

Atherosclerosis. One of the major causes of AAA is atherosclerosis, a disease characterized by chronic inflammation of the arterial wall. ${ }^{35}$ Based on the premise that atherosclerosis stimulates AAA, we hypothesized that CyPA would necessarily have a significant impact on atherosclerosis development. We have characterized five important pathological mechanisms by which CyPA promotes atherosclerosis (Figure 2). ${ }^{36}$ First, CyPA stimulates low-density lipoprotein (LDL) uptake in the vessel wall by regulating the expression of scavenger receptors. Second, CyPA increases EC activation and inflammation by increasing vascular cell 
adhesion molecule 1 (VCAM-1) expression. Third, CyPA decreases endothelial nitric oxide synthase (eNOS) expression through kruppel-like factor 2 (KLF2) transcriptional repression in EC. Fourth, CyPA is a key determinant for tumor necrosis factor alpha (TNF- $\alpha$ )-induced EC apoptosis. Finally, CyPA stimulates recruitment of inflammatory cells derived from the $\mathrm{BM}$ to the aortic wall.

Thus, CyPA may have an important role in several stages of atherosclerosis. This observation is also supported by recent papers suggesting that CyPA is involved in the early phase of

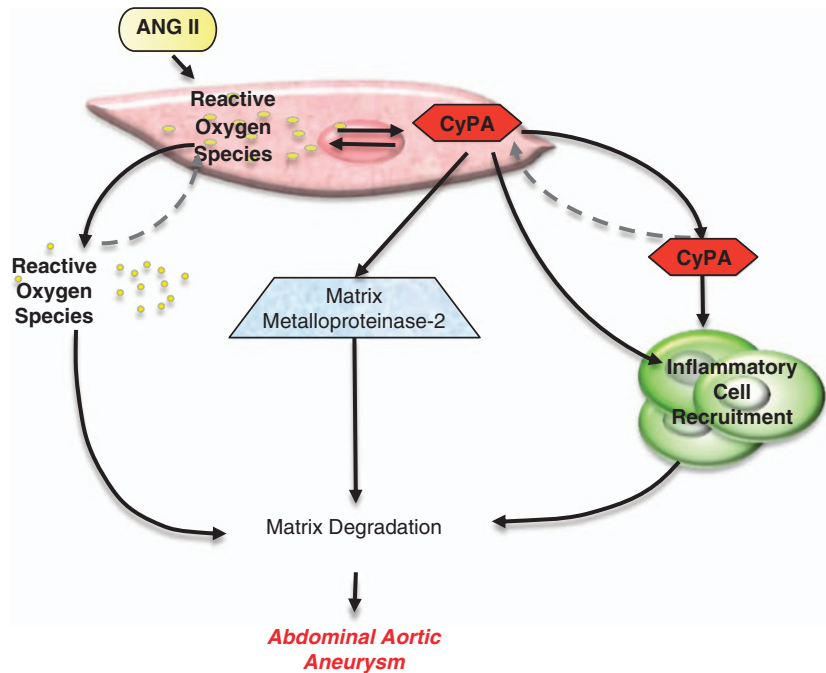

Figure 1 CyPA is involved in AAA formation. Ang Il induces ROS formation; this in turn determines the release of CyPA from VSMC. Extracellular CyPA contributes to the recruitment of inflammatory cells in the aneurysm site and the activation of MMPs that degrade the extracellular matrix. CyPA itself induces ROS formation by a positive feedback loop

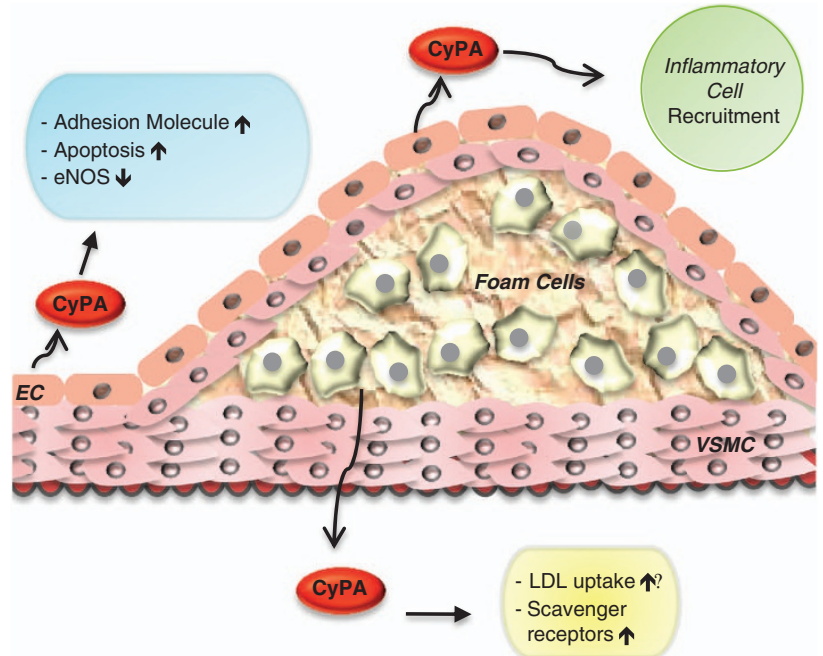

Figure 2 CyPA contributes to atherosclerosis formation. As atherosclerosis progresses, inflammation and ROS induce the release of CyPA from VSMC, EC and macrophages. Intracellular CyPA, as well as extracellular CyPA, influence LDL uptake by regulating the expression of scavenger receptors on the vessel wall. Also, CyPA induces inflammation of EC by increasing adhesion molecule expression and decreasing eNOS expression. In addition, CyPA increases the apoptosis of EC. Finally, CyPA induces the recruitment of inflammatory cells in atherosclerotic lesions atherosclerosis by regulating fatty streak formation, ${ }^{37}$ and later phases by affecting plaque rupture ${ }^{32,38}$ and thrombosis that complicate the disease..$^{39,40}$

Based on the literature reported above, it is now clear that CyPA is a crucial mediator of vascular remodeling, AAA, and atherosclerosis, three diseases that share common pathways (Figure 3).

Cardiac diseases. Inflammation triggered by oxidative stress is the cause of many human cardiac diseases including hypertrophy, myocardial ischemia, and coronary artery disease. ${ }^{41}$ Considering the role of CyPA in inflammation and ROS generation, we studied CyPA functions in heart disease. In particular, we evaluated the role of CyPA in Ang II-induced cardiac hypertrophy. ${ }^{42}$ Interestingly, mice lacking CyPA exhibited significantly less Ang II-induced cardiac hypertrophy. Most importantly, we proved that CyPA is required for Ang II-mediated cardiac hypertrophy by directly potentiating ROS production, stimulating the proliferation and migration of cardiac fibroblasts, and promoting cardiac myocyte hypertrophy.

In addition, May and coworkers ${ }^{43}$ demonstrated that CyPA is involved in myocardial ischemia and reperfusion injury.

Emerging data suggested that CyPA might be a valuable marker for predicting the severity of acute coronary syndromes. Yan et al. ${ }^{44}$ reported that serum CyPA concentration in unstable angina and acute myocardial infarction subjects are significantly higher than those in patients with stable angina and controls.

This study was confirmed by Satoh et al. ${ }^{45}$ that found that plasma levels of CyPA correlated with the anatomical severity of stable coronary artery disease.

In summary, CyPA is a critical determinant of cardiac hypertrophy, myocardial ischemia, and reperfusion injury and may be a helpful biomarker of coronary artery disease.

\section{CyPA and Diabetes}

Recently, Ramachandran et al. ${ }^{46}$ presented evidence for a significant role of CyPA in the pathogenesis of diabetes. They performed a proteomic analysis of high glucose-primed monocytes, and identified CyPA as a potential secretory marker of inflammation in type 2 diabetes. Specifically, they reported that CyPA expression is reduced in circulating monocytes from patients with type 2 diabetes. In addition, they found that the levels of CyPA in plasma samples of patients with diabetes and coronary artery disease are higher in comparison with plasma obtained from healthy volunteers. These data suggested that CyPA secreted from monocytes could be an important pro-inflammatory stimulus for vascular inflammation in patients with diabetes.

\section{CyPA and Viral Infection}

CyPA and human immunodeficiency virus (HIV-1). CyPA has been extensively studied from the gene to protein level during HIV-1 infection. CyPA is encoded by the peptidyl prolyl isomerase $\mathrm{A}(P P I A)$ gene, and regulatory PPIA polymorphisms were found to be a component of genetic susceptibility to HIV-1 infection or disease progression. ${ }^{47}$ In addition, analysis 


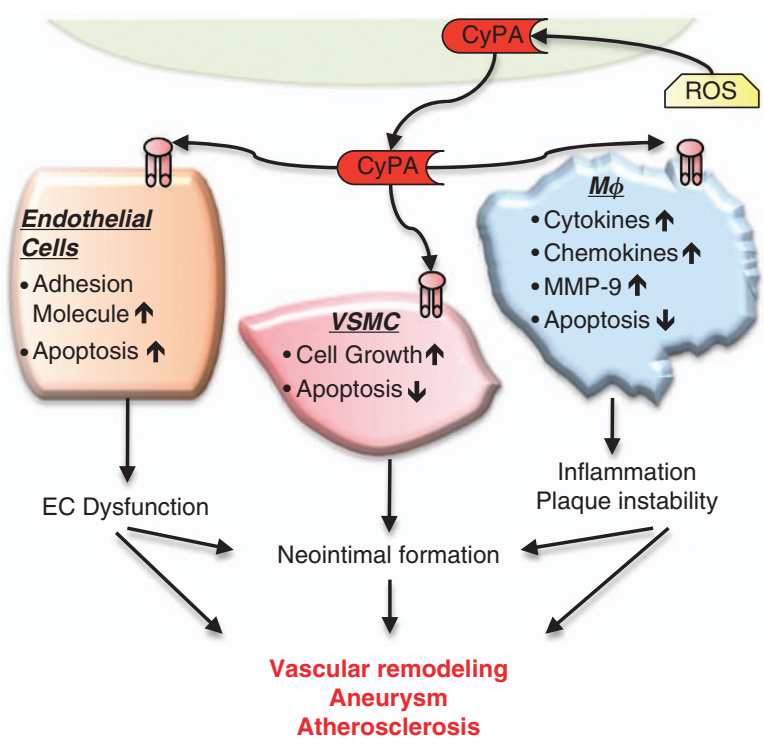

Figure 3 CyPA effects on EC, VSMC and macrophages. CyPA is secreted in response to ROS. Extracellular CyPA increases DNA synthesis and inhibits apoptosis in VSMC. In contrast, CyPA stimulates EC apoptosis, stimulates the expression of adhesion molecules including E-selectin and VCAM-1. Also, extracellular CyPA induces a pro-inflammatory status in macrophages by stimulating cytokines and chemokines production as well as inducing the activation of MMP-9 and decreasing apoptosis. These effects induce inflammation, EC dysfunction, neointimal formation thereby accelerating vascular remodeling, AAA and atherosclerosis

of sera from HIV-1-infected individuals has revealed higher protein concentrations of CyPA (about fourfold) compared with sera of healthy controls. ${ }^{48}$ Interestingly, HIV-1 replication was decreased in human CD4 ${ }^{+}$T cells when CyPA was knocked out. ${ }^{49}$ Molecular insights have revealed that CyPA can interact with HIV capsid proteins (CA domain). ${ }^{5}$ Furthermore, CyPA interacts with HIV accessory proteins, such as the viral protein $\mathrm{R}(\mathrm{Vpr})$ and Nef to facilitate a step in the viral life cycle between penetration and reverse transcription. ${ }^{50,51}$ Recently, it has been reported that CyPA in dendritic cells could recognize the newly synthesized HIV-1 CA domain and subsequently prompt an interferon type I (IFN-I) response through activation of IRF3. ${ }^{52}$ Therefore, packaging of host CyPA into HIV particles is an important step in HIV morphogenesis and essential for HIV replication.

CyPA and hepatitis virus. Similar to HIV-1, several lines of evidence indicate that CyPA positively regulates the replication of hepatitis $\mathrm{C}$ virus $(\mathrm{HCV}) .{ }^{53}$ Knockdown of endogenous CyPA significantly hampered HCV RNA replication and viral protein expression. ${ }^{54}$ Molecular studies provided evidence that CyPA enhances the replication of $\mathrm{HCV}$ by binding to the non-structural 5A (NS5A) and NS5B protein of HCV. ${ }^{55}$

CyPA is also important for hepatitis B virus (HBV) infection. Higher serum CyPA levels were detected in chronic hepatitis $B$ patients than in healthy individuals. ${ }^{56}$

Studies on molecular mechanisms regulating HBV replication showed that CyPA interacts with the small surface proteins
(SHBs) of the HBV surface antigen (HBsAg). ${ }^{56}$ It was hypothesized that CyPA binds to SHBs and is secreted along with HBsAg particles. ${ }^{53}$ Thus, CyPA may function as a cell-intrinsic sensor able to recognize HCV and HBV proteins in order to promote viral infection and replication.

CyPA and influenza A virus. CyPA was found in the core of the influenza virion ${ }^{57}$ and was upregulated upon infection by avian H9N2 influenza virus in AGS cells (a human gastric carcinoma cell line). ${ }^{58}$ Liu et al. ${ }^{59}$ revealed that overexpression of CyPA blocked influenza A virus replication, whereas the depletion of endogenous CyPA resulted in enhanced production of influenza A virus. Furthermore, CyPA was found to interact with the matrix protein 1 (M1) affecting the early stage of viral replication. Finally, CyPA was able to restrict influenza virus replication through accelerating degradation of the M1 protein.

CyPA and other viruses. It was reported that vaccinia virus (VV) infection led to an impressive increase in CyPA stability and CyPA is incorporated into the virus particle during morphogenesis. ${ }^{60}$ In addition, CyPA was found to act as a chaperone for the nucleocapsid protein of the vesicular stomatitis virus (VSV). ${ }^{61}$

CyPA was also reported to regulate severe acute respiratory syndrome coronavirus (SARS-CoV) replication through binding to the nucleocapsid protein and incorporation into particles. $^{62}$

Then, it was shown that CyPA is required for the host IFN-I response in rotavirus (RV) infection of MA104 cells. ${ }^{63}$ Finally, Keyes et al. ${ }^{64}$ demonstrated that CyPA expression is an important factor in human cytomegalovirus (HCMV) infection and reactivation.

In light of the major importance of CyPA in the regulation of infectivity and replication of several viruses, it is worth proposing CyPA as target for anti-viral therapy.

\section{Protozoan Parasites}

An emerging body of literature is reporting CyPA importance in the growth of protozoan parasites affecting humans. It has been suggested that the mammalian host cell CyPA seems to be involved in the intracellular replication cycle of Leishmania major parasites, as CyPA siRNA interference or CsA reduced the parasite burden. ${ }^{65}$ Some of the small CyPs from Plasmodium falciparum and Toxoplasma gondii (i.e. TgCyP18) have shown similar inhibitory profiles as those established for the human CyPA. ${ }^{66,67}$

The involvement of CyPA in protozoan parasite growth was also supported by the fact that CsA has anti-parasitic activity against a wide variety of parasites ${ }^{68}$ with the exception of Leishmania. $^{69}$

\section{CyPA and Cancer}

Upregulation of CyPA. There is now an established body of knowledge about the role of CyPA in cancer. Indeed, various reports have shown that CyPA is upregulated in cancer and is a key determinant for malignant transformation and metastasis. ${ }^{70,71}$ 
In small cell lung cancer, overexpressed CyPA stimulates cancer cell growth, whereas CyPA knockdown slows down cancer cell growth. ${ }^{70,72}$

CyPA is involved in diverse pathological processes of cancer development. Specifically, it has been reported that overexpressed CyPA in many cancers: (1) helps cancer proliferation, ${ }^{73}$ (2) regulates cell cycle progression, ${ }^{74}$ (3) blocks apoptosis, ${ }^{75}$ and (4) promotes cell migration/ invasion. $^{76}$

Interestingly, CyPA expression is influenced by chemotherapeutic agents. For example, treatment with anti-cancer drugs such as 5-aza-2-deoxycytidine, celecoxib, and 5-fluorouracil, decreases CyPA expression in cancer cells. ${ }^{77-79}$ Moreover, CsA and sanglifehrin A (SfA), the two immunosuppressive drugs that bind CyPA, increase the chemotherapeutic effect of cisplatin in glioblastoma multiforme. ${ }^{80}$

Transcriptional regulation of CyPA. Recently, upregulation of CyPA in cancers was reported to be controlled by p53 and $\mathrm{HIF} 1 \alpha$ (Figure 4), two critical transcription factors for cancer development. It was shown that CyPA protein is upregulated by p53-induced apoptotic conditions and CyPA may also confer p53 stability through its PPlase activity. ${ }^{81}$ However, overexpressed CyPA inhibits hypoxia- and cisplatininduced cell death in a p53- independent manner. Furthermore, it was found that, under hypoxic conditions, CyPA, whose promoter contains the hypoxia response element (HRE) motif, can be induced by HIF $1 \alpha .{ }^{75}$ Thus, the regulatory relations of CyPA with p53 and HIF1 $\alpha$ may present a new insight in understanding CyPA function during cancer development.

Drug resistance. Choi et al. ${ }^{75}$ also found that CyPA overexpression decreases cisplatin-induced cell death, whereas CyPA knockdown lower cell survival rates. These results suggested that CyPA overexpression may lead to

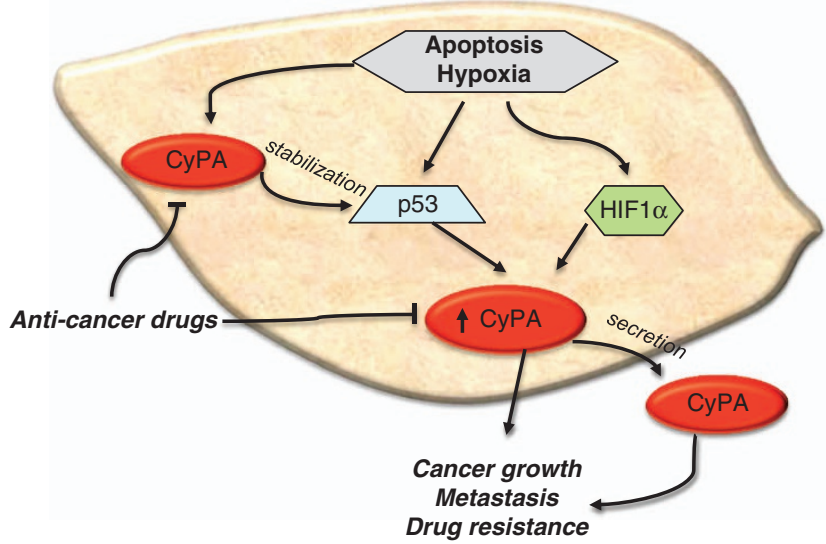

Figure 4 CyPA induces cancer growth. Apoptosis and hypoxia, through the activation of p53 and $\mathrm{HIF} 1 \alpha$, upregulate CyPA expression. This in turn stabilizes p53 protein. CyPA is also secreted by cancer cells and promotes cancer growth, metastasis and drug resistance. Anti-cancer drugs, such as DAC and 5-FU, decrease CyPA expression and thus block cancer progression. However, CyPA upregulation also decreases cisplatin-induced cell death suggesting that CyPA may lead to drug resistance drug resistance, which results in a bad outcome of chemotherapy. Subsequent oligo-microarray analysis by $\mathrm{Yu}$ and collaborators ${ }^{82}$ revealed that CyPA can upregulate the expression of many cytokine and drug resistance-related genes including drug metabolism and drug transport-related genes. Some of these genes, such as IL-6, multidrug resistance-associated protein 2 (MRP2), MRP3, microsomal glutathione $S$-transferase 1 (MGST1), and glutathione transferase zeta 1 (GSTZ1), may contribute to drug resistance. ${ }^{83}$ In addition, CyPA promoted the expression of many ATP-binding cassette (ABC) transporters, ${ }^{82}$ which are able to reduce cellular drug accumulation and consequently induce drug resistance. It was also observed that liver cells stably expressing CyPA (SK-Hep1-CyPA) show an increased resistance for the anti-cancer drugs doxorubicin and vincristine. Also, the accumulation of doxorubicin was reduced in SK-Hep1-CyPA cells. These data suggest that the elevated expression of CyPA may contribute to clinical resistance to chemotherapy.

In vivo studies. A report on CyPA in non-small-cell lung cancer revealed that CyPA knockdown has a significant effect on tumor growth in vivo. ${ }^{72}$ Two non-small-cell lung cancer cell lines, 5M2 and LC-103H, stably transfected with pSUPER-CyPA RNAi were grown as xenografts in severe combined immunodeficient (SCID) mice, and CyPA knockdown cells yielded slower-growing tumors than the cells transfected with scrambled RNAi. This effect was confirmed by overexpressing CyPA in the small airway epithelial cell line, S1LEK3. These cells resulted in faster growing xenografts in SCID mice compared with cells transfected with the empty vector. Large tumors were observed in the CyPA-overexpressing group, whereas none was observed in the vector group. ${ }^{72}$

Other interesting data by Li et al. ${ }^{73}$ revealed that intra-tumor injection of Pgenesil-2-CypA-shRNA decreases tumor development in nude mice. These data indicated that CyPA suppression by shRNA could significantly decrease tumor growth in vivo, with no apparent toxicity at the dose used.

\section{CyPA and Nervous System Degeneration}

Alzheimer disease. A growing body of evidence suggests oxidative stress involvement in neurodegenerative diseases. $^{84}$ In addition, many papers showed the contribution of CyPA in oxidative stress mediateddiseases. ${ }^{21,30,32}$ Recently Bell et al. $^{85}$ reported the involvement of CyPA in Alzheimer disease. In particular, they showed that astrocyte-derived human ApoE4 leads to an age-dependent progressive blood-brain barrier (BBB) breakdown (Figure 5). This event is driven by CyPA that initiates a pro-inflammatory pathway activating nuclear factor kappa B (NF- $\kappa$ B) and MMP-9. The activation of this pro-inflammatory pathway in brain capillary pericytes determines the release of neurotoxic molecules from the vessels, damaging neurons and affecting their synaptic connections.

Another recent paper by Kayenda et al. ${ }^{86}$ illustrated that the CD147 receptor, by interacting with CyPA, can influence amyloid- $\beta$ peptide levels, a protein that is central to 


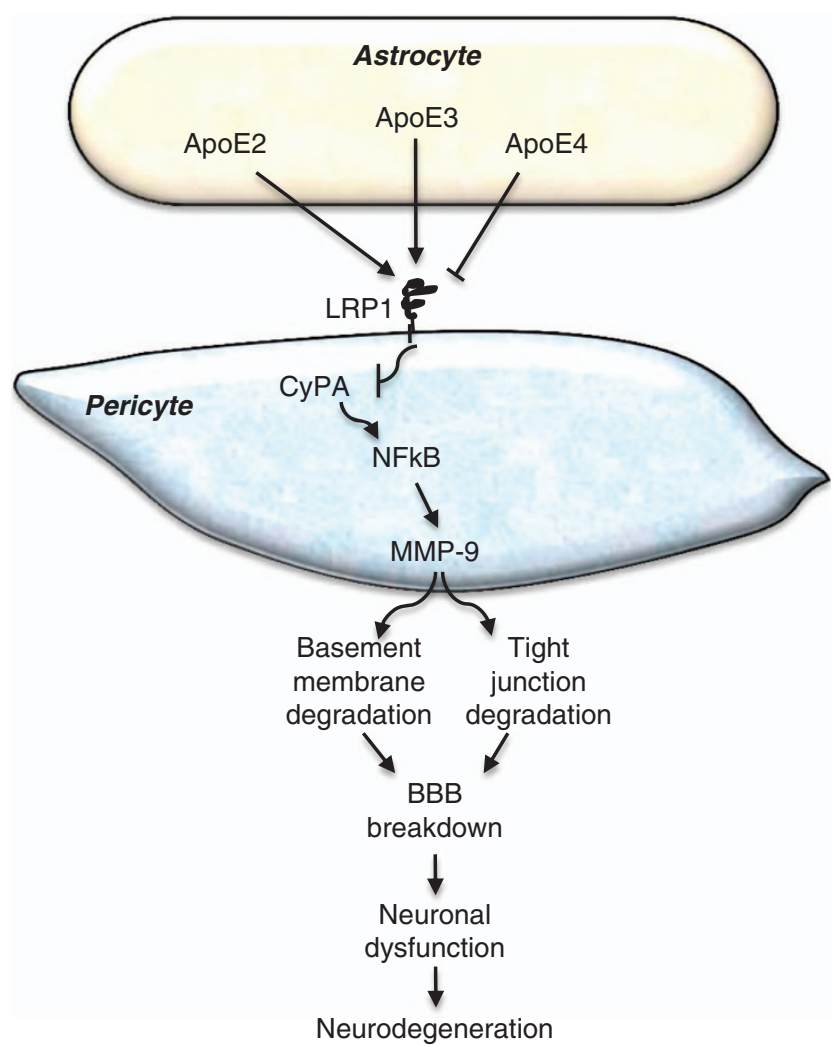

Figure 5 CyPA promotes neurodegeneration. ApoE2 and ApoE3 secreted by astrocytes, but not ApoE4, stimulates the low-density lipoprotein receptor-related protein 1 (LRP1) on pericytes. This event suppresses the pro-inflammatory pathway orchestrated by CyPA that leads to NF-kB and MMP-9 activation. As a consequence, the MMP-9-mediated degradation of tight junction and basement membrane proteins that causes BBB breakdown and neuronal dysfunction is inhibited

Alzheimer's disease pathogenesis. Furthermore, it has been shown that copper affects the secretion of CyPA. ${ }^{87}$ This mechanism is of particular relevance in the nervous system regulation as copper dyshomeostasis is responsible for the neurological symptoms observed in genetically inherited copper-dependent disorders (i.e., Menkes' and Wilson's diseases), as well as Alzheimer disease.

Amyotrophic lateral sclerosis (ALS). It has been reported that mutations in $\mathrm{Cu} / \mathrm{Zn}$ superoxide dismutase-1 (SOD1) can cause familial ALS. ${ }^{88}$ SOD1 transgenic mice that have the mutant human SOD1 (G93A) substitution are used as a model for ALS. Proteomic analysis of spinal cord of the G93A SOD1 mouse showed a variation in the isoform pattern of CyPA. ${ }^{89}$ In addition, overexpressed WT CyPA, but not CyPA with a rotamase active site point mutation, protected cells expressing ALS-related mutant SOD from death. ${ }^{90}$ Mechanistic insights revealed that CyPA is involved in motor neuronal cell death in ALS model mice by interacting with apoptosis-inducing factor (AIF). ${ }^{14}$ In particular, in the spinal cords of G93A SOD1 mice, the expressions of CyPA and AIF were detected in the motor neurons, and AIF co-translocated to the motor neuronal nuclei with CyPA. Furthermore, Basso et al. ${ }^{91}$ found that CyPA is significantly enriched in the insoluble fraction of spinal cords of ALS patients, thus may contribute to protein aggregate formation in ALS. Finally, Nardo et al. ${ }^{92}$ identified CyPA as biomarker for ALS in peripheral blood mononuclear cells and find an association with disease progression.

\section{CyPA and Rheumatoid Arthritis (RA)}

Of interest, RA has been the first condition in which a secreted form of CyPA has been demonstrated in extracellular fluids. As shown by Billich et al. ${ }^{93}$, CyPA was increased in the synovial fluids of RA patients compared with knee osteoarthritis patients. Won-Ha Lee and his colleagues ${ }^{94}$ extended the findings on CyPA in RA by demonstrating that macrophages of the synovial lining layer constitute the major source of CyPA. In addition, they showed that stimulation of monocytes with CyPA results in increased production of inflammatory cytokines. Yang et al. ${ }^{95}$ also suggested that in RA, the CyPA-CD147 interaction might contribute to the destruction of cartilage and bone by upregulating MMP-9 expression and adhesion of monocytes/macrophages to extracellular matrix. Similarly, Wang et al. ${ }^{96}$ suggested that CyPA significantly enhances the secretion of MMP-2 and MMP-9, cell invasion, and inflammatory cytokines production of monocytes.

Recently, it has been demonstrated that the increased expression of CD147 on neutrophils in RA may be responsible for CyPA-mediated neutrophil migration into the joints, elevated MMPs secretion, and cell invasion of synoviocytes. $^{97}$

Further, it was reported that CyPA affects IL-8-directed chemotaxis in neutrophils of RA patients. ${ }^{98}$

Altogether, these data are of interest because they tighten the links between CyPA and key pathological mechanisms of RA.

\section{CyPA and Sepsis}

After the discovery of CyPA as an extracellular mediator in $\mathrm{RA}$, the role of CyPA in other inflammatory diseases was evaluated. In 1997, Tegeder et al. ${ }^{99}$ reported that CyPA PPlase activity is significantly higher in patients with severe sepsis than healthy subjects. In addition, elevated PPlase activity was associated with high mortality. Then, Dear et al., ${ }^{100}$ by using a mouse model of sepsis based on cecal ligation and puncture, found that CyPA increased in abundance in the liver after sepsis. Moreover, Huang and collaborators ${ }^{101}$ reported that CyPA expression is modulated in peripheral lymphocytes from Pseudomonas aeruginosainduced sepsis ${ }^{101,102}$ and scalded rabbits caused by Staphylococcus aureus invasion. ${ }^{103}$

Finally, a comparative proteome analysis was performed on protein extracts from human monocyte THP-1 cells stimulated with either Lipoteichoic acid (LTA) from Staphylococcus aureus (aLTA) and from Lactobacillus plantarum LTA (pLTA). Interestingly, CyPA expression was significantly changed by aLTA- or pLTA stimulation. ${ }^{104}$

It is concluded that CyPA is a mediator in the pathophysiology of sepsis and might acquire a diagnostic value. 


\section{CyPA and Asthma}

Constant and collaborators, ${ }^{105}$ using a mouse model of asthmatic inflammation, showed a correlation between CyPA and asthma. In particular, they found that (1) extracellular CyPA is elevated in the airways of asthmatic mice; (2) CyPA induces CD147-dependent chemotaxis of activated $\mathrm{CD}^{+}{ }^{+} \mathrm{T}$ cells in vitro; (3) in vivo treatment with anti-CD147 mAb significantly reduces the accumulation of inflammatory cells in lung tissues; and (4) anti-CD147 treatment significantly reduces airway epithelial mucin production and bronchial hyperactivity to methacholine challenge.

Recently, Stemmy et al., ${ }^{106}$ by using a new murine model of chronic allergic asthma, found elevated concentrations of extracellular CyPA, but not classic chemokines, in the chronic phase of asthma. Also, blocking the activity of CyPA reduced the recruitment and persistence of leukocytes. Interestingly, it was reported that CyPA is present in nasal wash samples of asthmatic patients during the chronic phase of the disease and its levels associate with clinical parameters of disease severity. ${ }^{107}$

\section{CyPA and Periodontitis}

Recently Li et al. ${ }^{108}$ addressed the possible association of CyPA with pathological inflammation and destruction of periodontal tissues. They found that CyPA expression was dramatically elevated in inflamed gingival tissues as compared with healthy gingival tissues and co-localized in infiltrating macrophages and lymphocytes, as well as osteoclasts and osteoblasts in interradicular bone. As reported for other inflammatory diseases, CyPA expression correlated with MMP-1, MMP-2, and MMP-9 expression in inflamed gingiva. The same authors also collected gingival tissues and peripheral blood from patients with moderate to severe periodontitis or from healthy donors. ${ }^{109}$ CyPA was found to localize in the infiltrating cells and/or in the extracellular matrix in the inflamed gingival connective tissues. Also, CyPA was involved in the inflammatory response of periodontal tissues through inducing the chemotaxis of PBMCs/neutrophils and the secretion of TNF $\alpha /$ IL-8.

These data suggest that CyPA is associated with the inflammatory infiltration and alveolar bone destruction of periodontitis.

\section{CyPA and Aging}

Another interesting aspect of CyPA functions is its correlation with aging. Recently, Li et al. ${ }^{110}$ showed that the expression of CyPA increased with aging in normal skin, regardless of whether it was exposed or shaded. Similarly, it has been discovered that the expression level of CyPA is upregulated in the epidermis of aged people compared with younger people. ${ }^{111}$ Further, CyPA expression was found significantly higher in old rats than in the younger ones. ${ }^{112}$ In contrast, proteomic analysis of dermal fibroblasts cultured in vitro from human healthy subjects of different ages revealed that CyPA was markedly reduced with age, consistent with the reduced de novo synthesis of proteins and failure in performing biologically active conformational changes frequently observed during aging. ${ }^{113}$

\section{CyPA Inhibitors and Their Pharmacological Use}

As outlined above, CsA is a CyPA inhibitor and is the most well studied and tightest binding CyPA ligand identified to date. ${ }^{4}$ CsA binds both extracellular and intracellular CyPA and inhibits its PPlase activity. In particular, it inhibits the protein phosphatase calcineurin and blocks the translocation of nuclear factor from activated T cells (NF-AT) from the cytosol to the nucleus, thus preventing the transcription of genes encoding pro-inflammatory cytokines. ${ }^{114,115}$

Yurchenko et al. ${ }^{29}$ reported that CD147 interacts with extracellular CyPA in a CsA-sensitive fashion. Others showed that CsA blocks the folding of some proteins ${ }^{9,10}$ and modulates protein trafficking in cells. ${ }^{16,116,117}$

More importantly, CsA was shown by Borel et al. ${ }^{118}$ to be a potent and specific inhibitor of T-cell responses to alloantigens. This discovery led to widespread clinical use of CsA as an immunosuppressant, revolutionizing organ transplantation in humans. However, multiple side effects were observed with the long-term use of CsA in organ transplant recipients, especially severe nephrotoxicity, which remains one of the major obstacles for a broader use of the drug in the treatment of inflammation and other immune disorders. ${ }^{119}$

Thus, compounds that selectively inhibit CyPA without immunosuppressive effects are urgently required and might be applicable to the therapy of human diseases. In this case, treatment with isoenzyme specific inhibitors (1) would probably elicit fewer side effects than a global CyP inhibitor like CsA and (2) would not get dispersed into a cellular sink when sequestered by other CyPs.

Recently, scientists have synthesized derivatives of CsA that lack calcineurin-binding properties and thus do not exhibit immunosuppressive effects. The anti-inflammatory effect of these compounds is achieved because they directly block the proinflammatory and chemotactic functions of extracellular CyPA.

A growing body of scientific evidence has indicated that these non-immunosuppressive analogs of CsA may have applications in multiple therapeutic areas. In particular, they are among the most promising of the new anti-HCV agents under development. For example, Alisporivir (Debio 025) is the first-in-class CyPA inhibitor that recently initiated a phase III trial. It binds to CyPA and shows additive anti-viral effect with pegylated interferon-alpha $(\mathrm{plFN}-\alpha)$ in patients with genotype 1 and $4 \mathrm{HCV}^{120}$

In addition, another derivative of CsA, NIM811, has been shown to promise anti-inflammatory effects in different experimental models associated with inflammatory response, such as acute lung injury and arthritis. ${ }^{121,122}$

Another current challenge is to design therapeutic agents with the capacity to block specific functions of CyPA, while leaving other functions unaffected. In this context, a study reported the development of a small molecule with the capacity to specifically inhibit CyPA functions, without any effect on other CyP isoforms. ${ }^{123}$

Recently, a potent CyPA inhibitor, MM218, which can selectively inhibit the extracellular fraction of CyPA, has been 
synthesized. ${ }^{124}$ It appears to have a stronger anti-inflammatory effect than CsA, as well as no detectable adverse effects in an animal model of acute lung injury ${ }^{125}$ and myocardial reperfusion injury. ${ }^{126}$

It is hoped that the discovery of these novel selective drugs for CyPA might lead to a number of possible therapeutic applications in inflammatory disease.

\section{Conclusions and Perspectives}

Based on current knowledge reviewed above, it is now clear that CyPA has multi-functional properties. A number of biological studies demonstrated that CyPA is involved in various cellular functions including protein folding, trafficking, assembly, immune-modulation, and cell signaling. ${ }^{127}$

In light of what is known about CyPA, it is believed that an increase in CyPA expression contributes to pathological conditions. In fact, $\mathrm{CyPA}^{-1-}$ mice are protected from vascular remodeling, ${ }^{22}$ aortic aneurysm, ${ }^{32}$ atherosclerosis, ${ }^{36}$ cardiac hypertrophy, ${ }^{42}$ and ischemia/reperfusion injury. ${ }^{43}$ In addition, CyPA knockdown decreases tumor growth in vivo $^{72,73}$ and CyPA inhibitors are the most promising of the new ant-HCV agents. ${ }^{120}$ Furthermore, several studies suggested that high CyPA expression correlates with poor outcome of patients with inflammatory diseases. ${ }^{92,107,128}$

It is important to underline that both the intracellular and extracellular form of CyPA are involved in its pathogenic actions. Specifically, we found that, under inflammatory conditions, CyPA is secreted from cells and acts as an autocrine and paracrine factor that exacerbates oxidative stress and inflammation. ${ }^{22,32,42}$ However, extracellular CyPA has been found to have a biphasic effect, by promoting cell proliferation and migration at low doses and cytotoxic effects at higher doses. ${ }^{129}$

The mechanism by which CyPA contributes to the development of inflammatory diseases may involve a complex interplay of proteins and pathways including the membrane receptor for CyPA, CD147. However, it is worth mentioning that a number of mechanistic details are still unknown and await further studies. Indeed, to date CD147 has not been proven unequivocally to mediate all of the cellular events associated with CyPA. Thus, the identification of novel receptors for CyPA would be essential for future translational efforts aimed at targeting the CyPA pathway.

In conclusion, it is believed that the development of agents that selectively inactivate CyPA or that block binding of CyPA to its receptor could prove to be a fruitful approach to forestalling several human diseases.

\section{Conflict of Interest}

The authors declare no conflict of interest.

Acknowledgements. The authors are supported by funding from the FP7-PEOPLE-2011-CIG-294016 and National Institutes of Health RF-20102321151.

\footnotetext{
1. Wang P, Heitman J. The cyclophilins. Genome Biol 2005; 6: 226.

2. Lang K, Schmid FX, Fischer G. Catalysis of protein folding by prolyl isomerase. Nature 1987; 329: 268-270.
}

3. Dornan J, Taylor P, Walkinshaw MD. Structures of immunophilins and their ligand complexes. Curr Top Med Chem 2003; 3: 1392-1409.

4. Handschumacher RE, Harding MW, Rice J, Drugge RJ, Speicher DW. Cyclophilin: a specific cytosolic binding protein for cyclosporin A. Science 1984; 226: 544-547.

5. Luban J. Absconding with the chaperone: essential cyclophilin-Gag interaction in HIV-1 virions. Cell 1996; 87: 1157-1159.

6. Bosco DA, Eisenmesser EZ, Pochapsky S, Sundquist WI, Kern D. Catalysis of cis/trans isomerization in native HIV-1 capsid by human cyclophilin A. Proc Natl Acad Sci USA 2002; 99: 5247-5252.

7. Helekar SA, Char D, Neff S, Patrick J. Prolyl isomerase requirement for the expression of functional homo-oligomeric ligand-gated ion channels. Neuron 1994; 12: 179-189.

8. Helekar SA, Patrick J. Peptidyl prolyl cis-trans isomerase activity of cyclophilin A in functional homo-oligomeric receptor expression. Proc Natl Acad Sci USA 1997; 94: 5432-5437.

9. Steinmann B, Bruckner P, Superti-Furga A. Cyclosporin A slows collagen triple-helix formation in vivo: indirect evidence for a physiologic role of peptidyl-prolyl cis-transisomerase. J Biol Chem 1991; 266: 1299-1303.

10. Lodish HF, Kong N. Cyclosporin A inhibits an initial step in folding of transferrin within the endoplasmic reticulum. J Biol Chem 1991; 266: 14835-14838.

11. Shieh BH, Stamnes MA, Seavello S, Harris GL, Zuker CS. The ninaA gene required for visual transduction in Drosophila encodes a homologue of cyclosporin A-binding protein. Nature 1989; 338: 67-70.

12. Schneuwly S, Shortridge RD, Larrivee DC, Ono T, Ozaki M, Pak WL. Drosophila ninaA gene encodes an eye-specific cyclophilin (cyclosporine A binding protein). Proc Natl Acad Sci USA 1989; 86: 5390-5394.

13. Zhu C, Wang X, Deinum J, Huang Z, Gao J, Modjtahedi N et al. Cyclophilin A participates in the nuclear translocation of apoptosis-inducing factor in neurons after cerebral hypoxiaischemia. J Exp Med 2007; 204: 1741-1748.

14. Tanaka H, Shimazaki H, Kimura M, Izuta H, Tsuruma K, Shimazawa M et al. Apoptosisinducing factor and cyclophilin A cotranslocate to the motor neuronal nuclei in amyotrophic lateral sclerosis model mice. CNS Neurosci Ther 2011; 17: 294-304.

15. Pan H, Luo C, Li R, Qiao A, Zhang L, Mines $M$ et al. Cyclophilin A is required for CXCR4-mediated nuclear export of heterogeneous nuclear ribonucleoprotein A2, activation and nuclear translocation of ERK1/2, and chemotactic cell migration. $J$ Biol Chem 2008; 283: 623-637.

16. Yurchenko V, Pushkarsky T, Li JH, Dai WW, Sherry B, Bukrinsky M. Regulation of CD147 cell surface expression: involvement of the proline residue in the CD147 transmembrane domain. J Biol Chem 2005; 280: 17013-17019.

17. Huang T, Deng H, Wolkoff AW, Stockert RJ. Phosphorylation-dependent interaction of the asialoglycoprotein receptor with molecular chaperones. J Biol Chem 2002; 277 : 37798-37803.

18. Brown CR, Cui DY, Hung GG, Chiang HL. Cyclophilin A mediates Vid22p function in the import of fructose-1,6-bisphosphatase into Vid vesicles. J Biol Chem 2001; 276: 48017-48026.

19. Ansari $\mathrm{H}$, Greco G, Luban J. Cyclophilin A peptidyl-prolyl isomerase activity promotes ZPR1 nuclear export. Mol Cell Biol 2002; 22: 6993-7003.

20. Colgan J, Asmal M, Yu B, Luban J. Cyclophilin A-deficient mice are resistant to immunosuppression by cyclosporine. J Immunol 2005; 174: 6030-6038.

21. Jin ZG, Melaragno MG, Liao DF, Yan C, Haendeler J, Suh YA et al. Cyclophilin A is a secreted growth factor induced by oxidative stress. Circ Res 2000; 87: 789-796.

22. Satoh K, Matoba T, Suzuki J, O'Dell MR, Nigro P, Cui Z et al. Cyclophilin A mediates vascular remodeling by promoting inflammation and vascular smooth muscle cell proliferation. Circulation 2008; 117: 3088-3098.

23. Jin $Z G$, Lungu $A O$, Xie L, Wang $M$, Wong $C$, Berk BC. Cyclophilin A is a proinflammatory cytokine that activates endothelial cells. Arterioscler Thromb Vasc Biol 2004; 24 1186-1191.

24. Seko Y, Fujimura T, Taka H, Mineki R, Murayama K, Nagai R. Hypoxia followed by reoxygenation induces secretion of cyclophilin $A$ from cultured rat cardiac myocytes. Biochem Biophys Res Commun 2004; 317: 162-168.

25. Sherry B, Yarlett N, Strupp A, Cerami A. Identification of cyclophilin as a proinflammatory secretory product of lipopolysaccharide-activated macrophages. Proc Natl Acad Sci USA 1992; 89: 3511-3515

26. Suzuki J, Jin ZG, Meoli DF, Matoba T, Berk BC. Cyclophilin A is secreted by a vesicular pathway in vascular smooth muscle cells. Circ Res 2006; 98: 811-817.

27. Mittal N, Voldman J. Nonmitogenic survival-enhancing autocrine factors including cyclophilin A contribute to density-dependent mouse embryonic stem cell growth. Stem Cell Res 2011; 6: 168-176.

28. Xu Q, Leiva MC, Fischkoff SA, Handschumacher RE, Lyttle CR. Leukocyte chemotactic activity of cyclophilin. J Biol Chem 1992; 267: 11968-11971.

29. Yurchenko V, Zybarth G, O'Connor M, Dai WW, Franchin G, Hao T et al. Active site residues of cyclophilin A are crucial for its signaling activity via CD147. J Biol Chem 2002; 277: 22959-22965.

30. Satoh K, Nigro P, Berk BC. Oxidative stress and vascular smooth muscle cell growth: a mechanistic linkage by cyclophilin A. Antioxid Redox Signal 2010; 12: 675-682.

31. Dobrin PB, Baumgartner N, Anidjar S, Chejfec G, Mrkvicka R. Inflammatory aspects of experimental aneurysms. Effect of methylprednisolone and cyclosporine. Ann N Y Acad Sci 1996; 800: 74-88. 
32. Satoh K, Nigro P, Matoba T, O'Dell MR, Cui Z, Shi X et al. Cyclophilin A enhances vascular oxidative stress and the development of angiotensin II-induced aortic aneurysms. Nat Med 2009; 15: 649-656.

33. Prins PA, Perati PR, Kon V, Guo Z, Ramesh A, Linton MF et al. Benzo[a]pyrene potentiates the pathogenesis of abdominal aortic aneurysms in apolipoprotein $E$ knockout mice. Cell Physiol Biochem 2012; 29: 121-130.

34. Piechota-Polanczyk A, Demyanets S, Nykonenko O, Huk I, Mittlboeck M, Domenig CM et al. Decreased tissue levels of cyclophilin A, a cyclosporine A target and phospho-ERK1/2 in simvastatin patients with abdominal aortic aneurysm. Eur J Vasc Endovasc Surg 2013; 45 682-688.

35. Golledge J, Norman PE. Atherosclerosis and abdominal aortic aneurysm: cause, response, or common risk factors? Arterioscler Thromb Vasc Biol 2010; 30: 1075-1077.

36. Nigro P, Satoh K, O'Dell MR, Soe NN, Cui Z, Mohan A et al. Cyclophilin A is an inflammatory mediator that promotes atherosclerosis in apolipoprotein E-deficient mice. J Exp Med 2011; 208: 53-66.

37. Rezzani R, Favero G, Stacchiotti A, Rodella LF. Endothelial and vascular smooth muscle cell dysfunction mediated by cyclophylin $A$ and the atheroprotective effects of melatonin. Life Sci 2013; 92: 875-882.

38. Seizer P, Schonberger T, Schott M, Lang MR, Langer HF, Bigalke B et al. EMMPRIN and its ligand cyclophilin A regulate MT1-MMP, MMP-9 and M-CSF during foam cell formation. Atherosclerosis 2010; 209: 51-57.

39. Coppinger JA, Cagney G, Toomey S, Kislinger T, Belton O, McRedmond JP et al. Characterization of the proteins released from activated platelets leads to localization of novel platelet proteins in human atherosclerotic lesions. Blood 2004; 103: 2096-2104.

40. Elvers M, Herrmann A, Seizer P, Munzer P, Beck S, Schonberger T et al. Intracellular cyclophilin $\mathrm{A}$ is an important $\mathrm{Ca}(2+)$ regulator in platelets and critically involved in arterial thrombus formation. Blood 2012; 120: 1317-1326.

41. Griendling KK, FitzGerald GA. Oxidative stress and cardiovascular injury: part I: basic mechanisms and in vivo monitoring of ROS. Circulation 2003; 108: 1912-1916.

42. Satoh K, Nigro P, Zeidan A, Soe NN, Jaffre F, Oikawa M et al. Cyclophilin A promotes cardiac hypertrophy in apolipoprotein E-deficient mice. Arterioscler Thromb Vasc Biol 2011; 31: 1116-1123

43. Seizer $P$, Ochmann $C$, Schonberger $T$, Zach S, Rose M, Borst $O$ et al. Disrupting the EMMPRIN (CD147)-cyclophilin A interaction reduces infarct size and preserves systolic function after myocardial ischemia and reperfusion. Arterioscler Thromb Vasc Biol 2012 31: $1377-1386$.

44. Yan J, Zang X, Chen R, Yuan W, Gong J, Wang C et al. The clinical implications of increased cyclophilin A levels in patients with acute coronary syndromes. Clin Chim Acta 2012; 413: 691-695.

45. Satoh K, Fukumoto Y, Sugimura K, Miura Y, Aoki T, Nochioka K et al. Plasma cyclophilin A is a novel biomarker for coronary artery disease. Circ J 2013; 77: 447-455.

46. Ramachandran S, Venugopal A, Sathisha K, Reshmi G, Charles S, Divya G et al. Proteomic profiling of high glucose primed monocytes identifies cyclophilin A as a potential secretory marker of inflammation in type 2 diabetes. Proteomics 2012; 12 2808-2821.

47. An P, Wang LH, Hutcheson-Dilks H, Nelson G, Donfield S, Goedert JJ et al. Regulatory polymorphisms in the cyclophilin A gene, PPIA, accelerate progression to AIDS. PLOS Pathog 2007; 3: e88.

48. Endrich MM, Gehring $\mathrm{H}$. The V3 loop of human immunodeficiency virus type- 1 envelope protein is a high-affinity ligand for immunophilins present in human blood. Eur J Biochem 1998; 252: 441-446.

49. Braaten D, Luban J. Cyclophilin A regulates HIV-1 infectivity, as demonstrated by gene targeting in human T cells. EMBO J 2001; 20: 1300-1309.

50. Zander K, Sherman MP, Tessmer U, Bruns K, Wray V, Prechtel AT et al. Cyclophilin A interacts with HIV-1 Vpr and is required for its functional expression. J Biol Chem 2003; 278: 43202-43213

51. Qi M, Aiken C. Nef enhances HIV-1 infectivity via association with the virus assembly complex. Virology 2008; 373: 287-297.

52. Manel N, Hogstad B, Wang Y, Levy DE, Unutmaz D, Littman DR. A cryptic sensor for HIV-1 activates antiviral innate immunity in dendritic cells. Nature 2010; 467: 214-217.

53. Patient R, Hourioux C, Sizaret PY, Trassard S, Sureau C, Roingeard P. Hepatitis B virus subviral envelope particle morphogenesis and intracellular trafficking. J Virol 2007; 81 3842-3851.

54. Chatterji U, Bobardt M, Selvarajah S, Yang F, Tang H, Sakamoto $\mathrm{N}$ et al. The isomerase active site of cyclophilin $A$ is critical for hepatitis $C$ virus replication. J Biol Chem 2009; 284 16998-17005.

55. Tellinghuisen TL, Foss KL, Treadaway JC, Rice CM. Identification of residues required for RNA replication in domains II and III of the hepatitis C virus NS5A protein. J Virol 2008 82: 1073-1083.

56. Tian X, Zhao C, Zhu H, She W, Zhang J, Liu J et al. Hepatitis B virus (HBV) surface antigen interacts with and promotes cyclophilin a secretion: possible link to pathogenesis of HBV infection. J Virol 2010; 84: 3373-3381.

57. Shaw ML, Stone KL, Colangelo CM, Gulcicek EE, Palese P. Cellular proteins in influenza virus particles. PLoS Pathog 2008; 4: e1000085

58. Liu N, Song W, Wang P, Lee K, Chan W, Chen $\mathrm{H}$ et al. Proteomics analysis of differential expression of cellular proteins in response to avian H9N2 virus infection in human cells. Proteomics 2008; 8: 1851-1858.
59. Liu X, Sun L, Yu M, Wang Z, Xu C, Xue Q et al. Cyclophilin A interacts with influenza A virus M1 protein and impairs the early stage of the viral replication. Cell Microbiol 2009; 11: $730-741$.

60. Castro AP, Carvalho TM, Moussatche N, Damaso CR. Redistribution of cyclophilin A to viral factories during vaccinia virus infection and its incorporation into mature particles. J Virol 2003; 77: 9052-9068.

61. Bose S, Mathur M, Bates $P$, Joshi N, Banerjee AK. Requirement for cyclophilin A for the replication of vesicular stomatitis virus New Jersey serotype. J Gen Virol 2003; 84(Pt 7): 1687-1699.

62. Luo C, Luo H, Zheng S, Gui C, Yue L, Yu C et al. Nucleocapsid protein of SARS coronavirus tightly binds to human cyclophilin A. Biochem Biophys Res Commun 2004; 321: $557-565$.

63. He H, Zhou D, Fan W, Fu X, Zhang J, Shen Z et al. Cyclophilin A inhibits rotavirus replication by facilitating host IFN-I production. Biochem Biophys Res Commun 2012; 422: 664-669.

64. Keyes LR, Bego MG, Soland M St, Jeor S. Cyclophilin A is required for efficient human cytomegalovirus DNA replication and reactivation. J Gen Virol 2012; 93(Pt 4): 722-732.

65. Hoerauf A, Rascher C, Bang R, Pahl A, Solbach W, Brune K et al. Host-cell cyclophilin is important for the intracellular replication of Leishmania major. Mol Microbiol 1997; 24: 421-429.

66. Berriman M, Fairlamb $\mathrm{AH}$. Detailed characterization of a cyclophilin from the human malaria parasite Plasmodium falciparum. Biochem J 1998; 334(Pt 2): 437-445.

67. Golding H, Aliberti J, King LR, Manischewitz J, Andersen J, Valenzuela J et al. Inhibition of HIV-1 infection by a CCR5-binding cyclophilin from Toxoplasma gondii. Blood 2003; 102: 3280-3286.

68. Bell A, Monaghan P, Page AP. Peptidyl-prolyl cis-trans isomerases (immunophilins) and their roles in parasite biochemistry, host-parasite interaction and antiparasitic drug action. Int J Parasitol 2006; 36: 261-276.

69. Dutta M, Delhi P, Sinha KM, Banerjee R, Datta AK. Lack of abundance of cytoplasmic cyclosporin A-binding protein renders free-living Leishmania donovani resistant to cyclosporin A. J Biol Chem 2001; 276: 19294-19300.

70. Yang H, Chen J, Yang J, Qiao S, Zhao S, Yu L. Cyclophilin A is upregulated in small cell lung cancer and activates ERK1/2 signal. Biochem Biophys Res Commun 2007; 361: 763-767.

71. Qi YJ, He QY, Ma YF, Du YW, Liu GC, Li YJ et al. Proteomic identification of malignant transformation-related proteins in esophageal squamous cell carcinoma. J Cell Biochem 2008; 104: 1625-1635

72. Howard BA, Furumai R, Campa MJ, Rabbani ZN, Vujaskovic Z, Wang XF et al. Stable RNA interference-mediated suppression of cyclophilin A diminishes non-small-cell lung tumor growth in vivo. Cancer Res 2005; 65: 8853-8860.

73. Li Z, Zhao X, Bai S, Wang Z, Chen L, Wei Y et al. Proteomics identification of cyclophilin a as a potential prognostic factor and therapeutic target in endometrial carcinoma. Mol Cell Proteomics 2008; 7: 1810-1823.

74. Semba S, Huebner K. Protein expression profiling identifies cyclophilin A as a molecular target in Fhit-mediated tumor suppression. Mol Cancer Res 2006; 4: 529-538.

75. Choi KJ, Piao YJ, Lim MJ, Kim JH, Ha J, Choe W et al. Overexpressed cyclophilin A in cancer cells renders resistance to hypoxia- and cisplatin-induced cell death. Cancer Res 2007; 67: 3654-3662.

76. Calhoun CC, Lu YC, Song J, Chiu R. Knockdown endogenous CypA with siRNA in U2OS cells results in disruption of F-actin structure and alters tumor phenotype. Mol Cell Biochem 2009; 320: 35-43.

77. Cecconi D, Astner H, Donadelli M, Palmieri M, Missiaglia E, Hamdan M et al. Proteomic analysis of pancreatic ductal carcinoma cells treated with 5-aza-2'-deoxycytidine. Electrophoresis 2003; 24: 4291-4303.

78. Lou J, Fatima N, Xiao Z, Stauffer S, Smythers G, Greenwald P et al. Proteomic profiling identifies cyclooxygenase-2-independent global proteomic changes by celecoxib in colorectal cancer cells. Cancer Epidemiol Biomarkers Prev 2006; 15: 1598-1606.

79. Wong CS, Wong VW, Chan CM, Ma BB, Hui EP, Wong MC et al. Identification of 5 -fluorouracil response proteins in colorectal carcinoma cell line SW480 by two-dimensional electrophoresis and MALDI-TOF mass spectrometry. Oncol Rep 2008; 20: 89-98.

80. Han X, Yoon SH, Ding Y, Choi TG, Choi WJ, Kim YH et al. Cyclosporin A and sanglifehrin A enhance chemotherapeutic effect of cisplatin in C6 glioma cells. Oncol Rep 2010; 23 . 1053-1062

81. Yu X, Harris SL, Levine AJ. The regulation of exosome secretion: a novel function of the p53 protein. Cancer Res 2006; 66: 4795-4801.

82. Chen S, Zhang M, Ma H, Saiyin H, Shen S, Xi J et al. Oligo-microarray analysis reveals the role of cyclophilin A in drug resistance. Cancer Chemother Pharmacol 2008; 61: 459-469.

83. Blackburn AC, Coggan M, Tzeng HF, Lantum H, Polekhina G, Parker MW et al. GSTZ1d: a new allele of glutathione transferase zeta and maleylacetoacetate isomerase. Pharmacogenetics 2001; 11: 671-678.

84. Melo A, Monteiro L, Lima RM, Oliveira DM, Cerqueira MD, El-Bacha RS. Oxidative stress in neurodegenerative diseases: mechanisms and therapeutic perspectives. Oxid Med Cell Longev 2011; 2011: 467180

85. Bell RD, Winkler EA, Singh I, Sagare AP, Deane R, Wu Z et al. Apolipoprotein E controls cerebrovascular integrity via cyclophilin A. Nature 2012; 485: 512-516. 
86. Kanyenda LJ, Verdile G, Boulos S, Krishnaswamy S, Taddei K, Meloni BP et al. The dynamics of CD147 in Alzheimer's disease development and pathology. J Alzheimers Dis 2011; 26: 593-605.

87. Spisni E, Valerii MC, Manerba M, Strillacci A, Polazzi E, Mattia T et al. Effect of copper on extracellular levels of key pro-inflammatory molecules in hypothalamic GN11 and primary neurons. Neurotoxicology 2009; 30: 605-612.

88. Cookson MR, Menzies FM, Manning P, Eggett CJ, Figlewicz DA, McNeil CJ et al. Cu/Zn superoxide dismutase (SOD1) mutations associated with familial amyotrophic lateral sclerosis (ALS) affect cellular free radical release in the presence of oxidative stress. Amyotroph Lateral Scler Other Motor Neuron Disord 2002; 3: 75-85.

89. Massignan T, Casoni F, Basso M, Stefanazzi P, Biasini E, Tortarolo M et al. Proteomic analysis of spinal cord of presymptomatic amyotrophic lateral sclerosis G93A SOD1 mouse. Biochem Biophys Res Commun 2007; 353: 719-725.

90. Lee JP, Palfrey HC, Bindokas VP, Ghadge GD, Ma L, Miller RJ et al. The role of immunophilins in mutant superoxide dismutase-1linked familial amyotrophic lateral sclerosis. Proc Natl Acad Sci USA 1999; 96: 3251-3256.

91. Basso M, Samengo G, Nardo G, Massignan T, D'Alessandro G, Tartari S et al. Characterization of detergent-insoluble proteins in ALS indicates a causal link between nitrative stress and aggregation in pathogenesis. PLoS One 2009; 4: e8130.

92. Nardo G, Pozzi S, Pignataro M, Lauranzano E, Spano G, Garbelli S et al. Amyotrophic lateral sclerosis multiprotein biomarkers in peripheral blood mononuclear cells. PLoS One 2011; 6: e25545.

93. Billich A, Winkler G, Aschauer $H$, Rot A, Peichl P. Presence of cyclophilin A in synovial fluids of patients with rheumatoid arthritis. J Exp Med 1997; 185: 975-980.

94. Kim H, Kim WJ, Jeon ST, Koh EM, Cha HS, Ahn KS et al. Cyclophilin A may contribute to the inflammatory processes in rheumatoid arthritis through induction of matrix degrading enzymes and inflammatory cytokines from macrophages. Clin Immunol 2005; 116 : 217-224.

95. Yang Y, Lu N, Zhou J, Chen ZN, Zhu P. Cyclophilin A up-regulates MMP-9 expression and adhesion of monocytes/macrophages via CD147 signaling pathway in rheumatoid arthritis. Rheumatology (Oxford) 2008; 47: 1299-1310.

96. Wang L, Wang CH, Jia JF, Ma XK, Li Y, Zhu HB et al. Contribution of cyclophilin A to the regulation of inflammatory processes in rheumatoid arthritis. J Clin Immunol 2010; 30: 24-33.

97. Wang CH, Dai JY, Wang L, Jia JF, Zheng ZH, Ding J et al. Expression of CD147 (EMMPRIN) on neutrophils in rheumatoid arthritis enhances chemotaxis, matrix metalloproteinase production and invasiveness of synoviocytes. J Cell Mol Med 2011; 15: $850-860$.

98. Zhang $\mathrm{B}$, Wang $\mathrm{CH}$, Wang $\mathrm{YH}$, Fan $\mathrm{CM}$, Zhu $\mathrm{P}$. [The role of CyPA in chemotaxis of neutrophil in rheumatoid arthritis and secretion of interleukin-8]. Xi Bao Yu Fen Zi Mian Yi Xue Za Zhi 2009; 25: 423-425.

99. Tegeder I, Schumacher A, John S, Geiger H, Geisslinger G, Bang H et al. Elevated serum cyclophilin levels in patients with severe sepsis. J Clin Immunol 1997; 17: 380-386.

100. Dear JW, Leelahavanichkul A, Aponte A, Hu X, Constant SL, Hewitt SM et al. Liver proteomics for therapeutic drug discovery: inhibition of the cyclophilin receptor CD147 attenuates sepsis-induced acute renal failure. Crit Care Med 2007; 35: 2319-2328.

101. Zeng JZ, Zhang PH, Li LL, Ren LC, Liang PF, Huang XY. [Proteomic study of peripheral blood lymphocytes of rabbits with severe burn and Pseudomonas aeruginosa sepsis]. Zhongguo Wei Zhong Bing Ji Jiu Yi Xue 2009; 21: 455-459.

102. Zhang PH, Yang LR, Li LL, Zeng JZ, Ren LC, Liang PF et al. Proteomic change of peripheral lymphocytes from scald injury and Pseudomonas aeruginosa sepsis in rabbits. Burns 2010; 36: 82-88.

103. Zhang PH, Yang LR, Li LL, Zeng JZ, Huang XY. [Proteomic change in lymphocytes of scalded rabbits caused by Staphylococcus aureus invasion]. Zhonghua Shao Shang Za Zhi 2009; 25: 202-206.

104. Zeng RZ, Kim HG, Kim NR, Lee HY, Jung BJ, Ko MY et al. Protein expression changes in human monocytic THP-1 cells treated with lipoteichoic acid from Lactobacillus plantarum and Staphylococcus aureus. Mol Cells 2010; 29: 585-594.

105. Gwinn WM, Damsker JM, Falahati R, Okwumabua I, Kelly-Welch A, Keegan AD et al. Novel approach to inhibit asthma-mediated lung inflammation using anti-CD147 intervention. J Immunol 2006; 177: 4870-4879.

106. Stemmy EJ, Balsley MA, Jurjus RA, Damsker JM, Bukrinsky MI, Constant SL. Blocking cyclophilins in the chronic phase of asthma reduces the persistence of leukocytes and disease reactivation. Am J Respir Cell Mol Biol 2011; 45: 991-998.

107. Stemmy EJ, Benton AS, Lerner J, Alcala S, Constant SL, Freishtat RJ. Extracellular cyclophilin levels associate with parameters of asthma in phenotypic clusters. $J$ Asthma 2011; 48: 986-993.

108. Liu L, Li C, Cai C, Xiang J, Cao Z, Cyclophilin A. (CypA) is associated with the inflammatory infiltration and alveolar bone destruction in an experimental periodontitis. Biochem Biophys Res Commun 2010; 391: 1000-1006.
109. Liu L, Li C, Xiang J, Dong W, Cao Z. Over-expression and potential role of cyclophilin A in human periodontitis. J Periodontal Res 2013; 48: 615-622.

110. Li J, Xie H, Yi M, Peng L, Lei D, Chen X et al. Expression of cyclophilin A and CD147 during skin aging. Zhong Nan Da Xue Xue Bao Yi Xue Ban 2011; 36 203-211.

111. Gromov P, Skovgaard GL, Palsdottir H, Gromova I, Ostergaard M, Celis JE. Protein profiling of the human epidermis from the elderly reveals up-regulation of a signature of interferon-gamma-induced polypeptides that includes manganese-superoxide dismutase and the p85beta subunit of phosphatidylinositol 3-kinase. Mol Cell Proteomics 2003; 2 : 70-84.

112. Chen J, Rider DA, Ruan R. Identification of valid housekeeping genes and antioxidant enzyme gene expression change in the aging rat liver. J Gerontol A Biol Sci Med Sci2006; 61: 20-27.

113. Boraldi F, Bini L, Liberatori S, Armini A, Pallini V, Tiozzo R et al. Proteome analysis of dermal fibroblasts cultured in vitro from human healthy subjects of different ages. Proteomics 2003; 3: 917-929.

114. Emmel EA, Verweij CL, Durand DB, Higgins KM, Lacy E, Crabtree GR. Cyclosporin A specifically inhibits function of nuclear proteins involved in T cell activation. Science 1989; 246: $1617-1620$.

115. Flanagan WM, Corthesy B, Bram RJ, Crabtree GR. Nuclear association of a T-cell transcription factor blocked by FK-506 and cyclosporin A. Nature 1991; 352 : 803-807.

116. Shiraishi S, Yokoo H, Kobayashi H, Yanagita T, Uezono $Y$, Minami $S$ et al. Post-translational reduction of cell surface expression of insulin receptors by cyclosporin A, FK506 and rapamycin in bovine adrenal chromaffin cells. Neurosci Lett 2000; 293: 211-215.

117. Chklovskaia E, Nissen C, Landmann L, Rahner C, Pfister O, Wodnar-Filipowicz A. Cell-surface trafficking and release of flt3 ligand from $T$ lymphocytes is induced by common cytokine receptor gamma-chain signaling and inhibited by cyclosporin A. Blood 2001; 97: 1027-1034.

118. Borel JF, Feurer $\mathrm{C}$, Magnee $\mathrm{C}$, Stahelin $\mathrm{H}$. Effects of the new anti-lymphocytic peptide cyclosporin A in animals. Immunology 1977; 32: 1017-1025.

119. Stahelin HF. The history of cyclosporin A (Sandimmune) revisited: another point of view. Experientia 1996; 52: 5-13.

120. Flisiak R, Feinman SV, Jablkowski M, Horban A, Kryczka W, Pawlowska M et al. The cyclophilin inhibitor Debio 025 combined with PEG IFNalpha2a significantly reduces viral load in treatment-naive hepatitis C patients. Hepatology 2009; 49: 1460-1468.

121. Arora K, Gwinn WM, Bower MA, Watson A, Okwumabua I, MacDonald HR et al. Extracellular cyclophilins contribute to the regulation of inflammatory responses. $\mathrm{J}$ Immunol 2005; 175: 517-522.

122. Damsker JM, Okwumabua I, Pushkarsky T, Arora K, Bukrinsky MI, Constant SL. Targeting the chemotactic function of CD147 reduces collagen-induced arthritis. Immunology 2009; 126: 55-62.

123. Mori $T$, Itami S, Yanagi T, Tatara $Y$, Takamiya M, Uchida $T$. Use of a real-time fluorescence monitoring system for high-throughput screening for prolyl isomerase inhibitors. J Biomol Screen 2009; 14: 419-424.

124. Malesevic M, Kuhling J, Erdmann F, Balsley MA, Bukrinsky MI, Constant SL et al. A cyclosporin derivative discriminates between extracellular and intracellular cyclophilins. Angew Chem. Int Ed Engl 2010; 49: 213-215.

125. Balsley MA, Malesevic M, Stemmy EJ, Gigley J, Jurjus RA, Herzog D et al. A cell-impermeable cyclosporine A derivative reduces pathology in a mouse model of allergic lung inflammation. J Immunol 2010; 185: 7663-7670.

126. Wang WL, Yuan YJ, Xue FS, Liao X, Wang Q, Xiong J et al. Extracellular cyclophilin A may be a potential target to protect against myocardial reperfusion injury. Med Hypotheses 2011; 77: 734-738.

127. Galat A. Peptidylproline cis-trans-isomerases: immunophilins. Eur J Biochem 1993; 216: 689-707.

128. Obchoei S, Wongkhan S, Wongkham C, Li M, Yao Q, Chen C et al. potential functions and therapeutic target for human cancer. Med Sci Monit 2009; 15: RA221-RA232.

129. Kim SH, Lessner SM, Sakurai Y, Galis ZS. Cyclophilin A as a novel biphasic mediator of endothelial activation and dysfunction. Am J Pathol 2004; 164: 1567-1574.

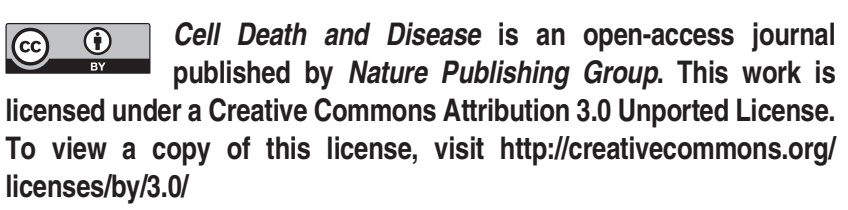

